\title{
Centronuclear Myopathy 1
}

National Cancer Institute

\section{Source}

National Cancer Institute. Centronuclear Myopathy 1. NCI Thesaurus. Code C126689.

A myopathy inherited in an autosomal dominant or recessive pattern, caused by mutations in the DNM2, BIN1, and TTN genes. Microscopically there is central displacement of the nucleus in muscle cells. It is characterized by muscle weakness and atrophy in the skeletal muscles. 